\title{
Contrasted patterns of genetic variation in the dogwhelk Nucella lapillus along two putative post-glacial expansion routes
}

\author{
Isabelle Colson ${ }^{1,2}$, Roger N. Hughes ${ }^{1, *}$ \\ ${ }^{1}$ School of Biological Sciences, University of Wales, Bangor, Deiniol Road, Bangor LL57 2UW, UK \\ ${ }^{2}$ Present address: Zoologisches Institut, Evolutionsbiologie, Universität Basel, Vesalgasse 1, 4051 Basel, Switzerland
}

\begin{abstract}
During the last glacial maximum, the dogwhelk Nucella lapillus, like many other rocky shore species, was eradicated from the west Atlantic and largely confined to southern refugia in the east Atlantic. Using microsatellite markers, we studied the geographical distribution of population genetic diversity of $N$. lapillus along 2 putative post-glacial expansion routes: northward along the east Atlantic shores of Europe, and westward across the Atlantic via Iceland to North America. The patterns of genetic diversity and genetic structure along these 2 routes indicate that the "transAtlantic" expansion involved a stepping-stone migration from Europe to Iceland to North America, with rare long-distance dispersal causing serial bottleneck effects. Along the east Atlantic route, however, long-distance dispersal seems to have occurred more often. These observations, underpinned by hydrography, suggest that rafting could be a major agent of dispersal for marine species lacking planktonic life stages.
\end{abstract}

KEY WORDS: Nucella lapillus $\cdot$ Phylogeography $\cdot$ Post-glacial expansion · Dispersal $\cdot$ Hydrography

\section{INTRODUCTION}

Quaternary ice ages played a major role in shaping the genetic structure of high-latitude communities and species. Rapid climatic oscillations produced wide changes in species distribution, with many boreal and temperate species finding refuge southward during glacial stages, and re-expanding northward as the ice retreated. These population contraction/expansion cycles left a noticeable signature in the genetic structure of modern populations, notably a decrease in genetic diversity at higher latitudes (Hewitt 2000). In many cases, however, the genetic effects of contraction/expansion cycles are more complex and depend on various ecological, geographical and demographic factors. The number and intensity (England et al. 2003) of bottleneck events will affect genetic diversity differently. Post-bottleneck increase in genetic diversity will also depend on the rate of subsequent population growth (Nei et al. 1975). It is particularly important to consider this last effect when studying historical events such as post-glacial expansions, when the time elapsed since the bottleneck is long enough for new mutations to occur; this applies particularly in genetic markers with high mutation rates, such as microsatellites. Because of this underlying complexity, a hypothesisbased approach is needed, with statistical tests of specific predictions about the patterns of genetic variation, rather than ad hoc explanations of observed patterns.

Despite the stochasticity and complexity of factors underlying the geographical distribution of genetic variation, accumulation of data from many independent studies has yielded important insights, such as the location of glacial refugia and routes of post-glacial expansion at the continental level in terrestrial biota (Hewitt 2000), and there is little doubt that the addition of new species and genetic markers will refine patterns further. Studies of post-glacial expansion of marine organisms have lagged somewhat behind those of terrestrial species. The lack of obvious physical barriers in marine ecosystems led to the expectation that widely dispersing marine species would show little genetic structure 
(Bohonak 1999). Recent data on the population genetics of marine taxa are challenging this simplistic view, however, and the discipline of marine phylogeography is now a rapidly expanding field. A long-standing paradigm posits a relationship between larval dispersal and population genetic structuring. If indeed there is such a general correlation (Colson \& Hughes 2004), the relationship between dispersal capacity, mode of development and population genetic structuring is complex, including cases where observed levels of structuring either exceed (Govindarajan et al. 2005) or fall short of (Colson \& Hughes 2004) those predicted. Clearly, many more phylogeographic studies are needed if the general level of understanding of post-glacial colonization patterns for marine organisms is to approach that achieved for terrestrial counterparts.

Here we address post-glacial expansion in the North Atlantic of the dogwhelk Nucella lapillus, a directdeveloping intertidal gastropod restricted to rocky shores. N. lapillus is the sole North Atlantic representative of its genus, and is a common predatory gastropod of the lower rocky intertidal zone. Encapsulated eggs, attached in clusters to rocky substrata, hatch into small $(<2 \mathrm{~mm})$ fully-formed crawl-aways. The lack of a planktonic larval phase and the reduced mobility of adults should imply very low dispersal ability. In contradiction to this expectation, genetic analysis of recent populations which had re-established after local extinction, indicated that recolonization was not associated with strong bottlenecks, thus suggesting a relatively high level of migration at local scales of tens of kilometres (Colson \& Hughes 2004). The present distribution of $N$. lapillus extends across the North Atlantic, from southern Portugal to Novaya Zemlya in the east, SW Iceland and the east American coast from Newfoundland to Long Island in the west. Isolated populations have also been reported in Greenland (Mörch 1857, Kristensen \& Petersen 1977). Like many other temperate and boreal species restricted to rocky shores, N. lapillus disappeared from the American continent during the last glacial maximum (LGM), around 18000 years BP (Ingolfsson 1992), due to the lack of suitable rocky habitat south of the American ice sheet. In eastern North America, the ice reached as far south as $40^{\circ} \mathrm{N}$ (Hewitt 2000). In many cases, new colonists reached the American coast from Europe across the Atlantic Ocean (Ingolfsson 1992). A study of mitochondrial DNA diversity suggests that this is the case for $N$. lapillus (Wares \& Cunningham 2001). Levels of genetic diversity in mitochondrial genes, however, are relatively low in N. lapillus (Wares \& Cunningham 2001), and yield insufficient resolution for a detailed study. We therefore used microsatellite markers to test specific hypotheses about the patterns of postglacial expansion in N. lapillus. Assuming 2 major expansion routes, one from a southern European refugium northward along the East Atlantic coast, and one from Europe to North America across the Atlantic Ocean via Iceland, we tested our data against expectations of various demographic and dispersal models.

Under a stepping-stone model of dispersal, we expect to observe a pattern of isolation by distance along the expansion route (Kushta \& Tan 2004) together with a decrease in genetic diversity, depending on the rate of migration and population recovery. The cline in genetic diversity should be steepest under a model of leptokurtic dispersal, i.e. with a small number of long-distance migration events (Clark 1998). Under an island model of dispersal, with many migration events from several source populations, we can expect a much smaller decrease in genetic diversity along the expansion route, and no significant isolation by distance.

Any conclusions about clines of genetic diversity, however, may be strongly contingent upon the choice of estimators. In the case of rapidly mutating markers such as microsatellites, the occurrence of mutations after recolonization will lead to a secondary increase of genetic diversity, especially in rapidly growing populations (Nei et al. 1975). On the other hand, assuming a mutation model of microsatellites with some memory in allele size (such as a stepwise or 2-phase mutation model), the distribution of allele size frequencies after population growth from a few pioneers will have a lower variance than in a population of constant size (Balloux \& Lugon-Moulin 2002). As a result, the variance in repeat number of a growing population will increase more slowly than allelic or gene diversity. Based on the above hypotheses and methodological counterchecking, our study of the global genetic structure of Nucella lapillus populations should reveal the geographical patterns of post-glacial expansion.

\section{MATERIALS AND METHODS}

Populations sampled. From 2002 to 2004, a total of 362 individuals were collected from 10 localities spanning most of the present distribution of the species. To account for local differentiation, 2 sites were sampled from each locality, except in the case of Tromsø and Long Island, where individuals were collected from one site only. Finally, individuals were collected from the 2 known Greenlandic populations (Table 1). Sample sizes varied from 20 to 30 individuals per site, except in Galicia and Maine, where the number of genotyped individuals per site was much smaller (15 and 10 respectively). Differentiation between sites within localities was low (see 'Results'), justifying pooling data within localities for analysis of genetic structure. 
Table 1. Nucella lapillus. Geographical location and genetic diversity of populations sampled. N: sample size; He: mean gene diversity; $\mathrm{A}$ : mean allelic diversity; $\mathrm{V}_{\mathrm{R}}$ : mean variance in repeat numbers; nd: no data

\begin{tabular}{|c|c|c|c|c|c|c|c|c|c|}
\hline $\begin{array}{l}\text { Population } \\
\text { label }\end{array}$ & Locality & Site & Latitude & Longitude & $\begin{array}{c}\text { Shore } \\
\text { exposure }\end{array}$ & $\mathrm{N}$ & $\mathrm{He}$ & A & $\mathrm{V}_{\mathrm{R}}$ \\
\hline GAL1 & Northern Spain (Galicia) & Silleiro & $42^{\circ} 14^{\prime} \mathrm{N}^{\mathrm{a}}$ & $8^{\circ} 43^{\prime} \mathrm{W}^{\mathrm{a}}$ & Sheltered & 15 & 0.76 & 6.81 & 19.79 \\
\hline GAL2 & Northern Spain (Galicia) & Cabe Home & $42^{\circ} 14^{\prime} \mathrm{N}^{\mathrm{a}}$ & $8^{\circ} 43^{\prime} \mathrm{W}^{\mathrm{a}}$ & Exposed & 15 & 0.76 & 7.44 & 18.21 \\
\hline SWE1 & South-west England & St. Agnes & $50^{\circ} 19^{\prime} \mathrm{N}$ & $5^{\circ} 18^{\prime} \mathrm{W}$ & Sheltered & 24 & 0.69 & 6.40 & 17.23 \\
\hline SWE2 & South-west England & Stoke Beach & $50^{\circ} 17^{\prime} \mathrm{N}$ & $4^{\circ} 07^{\prime} \mathrm{W}$ & Sheltered & 24 & 0.70 & 6.40 & 14.95 \\
\hline WAL1 & North-west Wales & Menai Bridge & $53^{\circ} 14^{\prime} \mathrm{N}$ & $4^{\circ} 10^{\prime} \mathrm{W}$ & Sheltered & 20 & 0.61 & 4.35 & 14.39 \\
\hline WAL2 & North-west Wales & Trecastell & $53^{\circ} 14^{\prime} \mathrm{N}$ & $4^{\circ} 31^{\prime} \mathrm{W}$ & Exposed & 20 & 0.69 & 6.15 & 19.17 \\
\hline SCO1 & South-west Scotland & Millport 1 & $55^{\circ} 46^{\prime} \mathrm{N}$ & $4^{\circ} 55^{\prime} \mathrm{W}$ & Sheltered & 24 & 0.63 & 5.74 & 20.43 \\
\hline $\mathrm{SCO} 2$ & South-west Scotland & Millport 2 & $55^{\circ} 46^{\prime} \mathrm{N}$ & $4^{\circ} 55^{\prime} \mathrm{W}$ & Sheltered & 24 & 0.61 & 5.17 & 17.45 \\
\hline NEE1 & North-east England & Blackhalls & $54^{\circ} 45^{\prime} \mathrm{N}$ & $1^{\circ} 17^{\prime} \mathrm{W}$ & Sheltered & 24 & 0.55 & 4.79 & 16.02 \\
\hline NEE2 & North-east England & Saltburn & $54^{\circ} 35^{\prime} \mathrm{N}$ & $0^{\circ} 58^{\prime} \mathrm{W}$ & Sheltered & 24 & 0.58 & 5.31 & 20.09 \\
\hline TRO & Northern Norway & Tromsø & $69^{\circ} 40^{\prime} \mathrm{N}$ & $18^{\circ} 58^{\prime} \mathrm{E}$ & nd & 20 & 0.63 & 4.93 & 17.16 \\
\hline ICE1 & South-west Iceland & Reijkjavik1 & $64^{\circ} 08^{\prime} \mathrm{N}^{\mathrm{a}}$ & $21^{\circ} 54^{\prime} \mathrm{W}^{\mathrm{a}}$ & Sheltered & 20 & 0.51 & 4.23 & 11.53 \\
\hline ICE2 & South-west Iceland & Reijkjavik2 & $64^{\circ} 08^{\prime} \mathrm{N}^{\mathrm{a}}$ & $21^{\circ} 54^{\prime} \mathrm{W}^{\mathrm{a}}$ & Exposed & 20 & 0.46 & 3.74 & 10.42 \\
\hline GRE1 & South-west Greenland & Nerutusok fjord & $62^{\circ} 12^{\prime} \mathrm{N}$ & $49^{\circ} 30^{\prime} \mathrm{W}$ & Sheltered & 20 & 0.36 & 3.18 & 8.22 \\
\hline GRE2 & South-west Greenland & Tartog fjord & $60^{\circ} 50^{\prime} \mathrm{N}$ & $45^{\circ} 55^{\prime} \mathrm{W}$ & Sheltered & 30 & 0.29 & 3.08 & 5.73 \\
\hline MAI1 & Maine & Thompson Island & $44^{\circ} 26^{\prime} \mathrm{N}$ & $68^{\circ} 22^{\prime} \mathrm{W}$ & Sheltered & 9 & 0.49 & 3.16 & 7.38 \\
\hline MAI2 & Maine & Ship Harbor & $44^{\circ} 14^{\prime} \mathrm{N}$ & $68^{\circ} 21^{\prime} \mathrm{W}$ & Exposed & 10 & 0.49 & 3.64 & 5.38 \\
\hline LGI & Long Island & Long Island & $40^{\circ} 45^{\prime} \mathrm{N}$ & $73^{\circ} 57^{\prime} \mathrm{W}$ & nd & 19 & 0.28 & 2.83 & 6.12 \\
\hline
\end{tabular}

Model predictions. We tested the predictions regarding genetic diversity and genetic structure of 3 distinct models of post-glacial expansion (Table 2). The unidirectional stepping stone model of dispersal assumes a stepping stone expansion accompanied by strong bottlenecks. In this case, we expect to observe a strong decrease in genetic diversity along the expansion route, and therefore a significant negative correlation between the genetic diversity parameters of populations and their distance to the refugium (assumed here to be in Galicia, the southernmost population sampled). Subsequent population expansions might lead to an increase in gene diversity $(\mathrm{He})$ and allelic diversity $(A)$, but not of variance in repeat number $\left(V_{R}\right)$ (Balloux \& Lugon-Moulin 2002). Restricted dispersal also implies that the accumulation of genetic differentiation following each bottleneck event will lead to a

Table 2. Nucella lapillus. Expected spatial patterns of genetic diversity and genetic structure under 3 models of post-glacial expansion from refugia. The models are described in 'Materials and methods'. Correlations: correlation with distance from refugium. He: mean gene diversity; $A$ : mean allelic diversity; $V_{R}$ : mean variance in repeat numbers; ibd: isolation by distance

\begin{tabular}{|lcccc|}
\hline \multirow{2}{*}{$\begin{array}{l}\text { Para- } \\
\text { meters }\end{array}$} & \multicolumn{3}{c}{ Models of dispersal } & \\
\cline { 2 - 3 } & Stepping-stone & Multiple source & \\
\hline $\mathrm{He}$ & Negative correlation & Negative correlation & No negative correlation \\
$\mathrm{A}$ & Negative correlation & Negative correlation & No negative correlation \\
$\mathrm{V}_{\mathrm{R}}$ & Negative correlation & No negative correlation & No negative correlation \\
ibd & Yes & No & No \\
& & & & \\
\hline
\end{tabular}

pattern of isolation by distance (Kushta \& Tan 2004). Our second model is also unidirectional, but allows for recolonization from multiple sources and a higher frequency of long-distance dispersal events. In this case, we would expect to observe a lower correlation of genetic diversity with distance from the refugium, depending on the rate of migration and the differential contribution of each source population. In particular, in the case of multiple source populations each contributing divergent alleles to the sink population, we would expect the $V_{R}$ values not to decrease with distance from the refugium. We also expect to observe a lower level of, or no isolation by distance. Finally, under an island model, migration occurs between all populations, with no preferential direction. In such a case, no cline in genetic diversity or isolation by distance will be observed, but as we assume a directional route of migration this model has no real biological meaning here. High nondirectional migration after recolonisation would lead to similar expected observations, but again such a situation is very unlikely in the case of a species lacking a planktonic phase.

Genetic diversity. DNA extraction and genotyping were carried out as described previously (Colson \& Hughes 2004). Each individual was genotyped at 9 microsatellite loci: Nlw2, Nlw3, Nlw8, Nlw11, Nlw14, Nlw17, Nlw21, Nlw25 and Nlw27 (Kawai et al. 2001). Allele frequen- 
cies, He (corrected for sample size), expected A under the stepwise mutation model (SMM) and $V_{R}$ (corrected for sample size) were computed with the MSA software (Dieringer \& Schlötterer 2003). Diversity statistics were regressed on the distance from the putative refugium population (in this case, the Spanish locality) for each assumed expansion route. The east Atlantic route comprises sites from the European coast (GAL-SWE-WAL-SCO-NEE-TRO), whereas the trans-Altlantic route comprises populations from south-west Europe, the Atlantic coast of the British Isles, Iceland, Greenland and the East coast of America (GAL-SWE-WAL-SCO-ICE-GREMAI-LGI) (Fig. 1).

Genetic structure. For all analyses of genetic structure, with the exception of the Neighbour-Joining tree construction, sampling sites within localities were pooled as differentiation within locality was low (see 'Results'). F and R statistics (Slatkin 1995) were computed with the FSTAT software (Goudet 1995). Because the $\mathrm{F}_{\mathrm{ST}}$ and $\mathrm{R}_{\mathrm{ST}}$ statistics perform differently under different assumptions and conditions (Balloux \& Lugon-Moulin 2002), 2 different estimators of Fst (Nei 1973, Weir \& Cockerham 1984) and $\mathrm{R}_{\mathrm{ST}}$ (Rousset 1996, Goodman 1997) were compared for the following population groupings: global, east Atlantic, west Atlantic + Iceland, and Greenland. The genetic distances between pooled populations from the east and west Atlantic were also computed using the same estimators. In general, $\mathrm{R}_{\mathrm{ST}}$ will perform better at detecting higher structuring, whereas $\mathrm{F}_{\mathrm{ST}}$ will be deflated when gene flow is low and mutation rate is high (Balloux \& Lugon-Moulin 2002). On the other hand, the use of $R_{S T}$ rests on an assumption of a strict stepwise mutation model of microsatellite markers, which is unrealistic in many cases (Colson \& Goldstein 1999). Isolation by distance along the 2 routes was estimated with Mantel

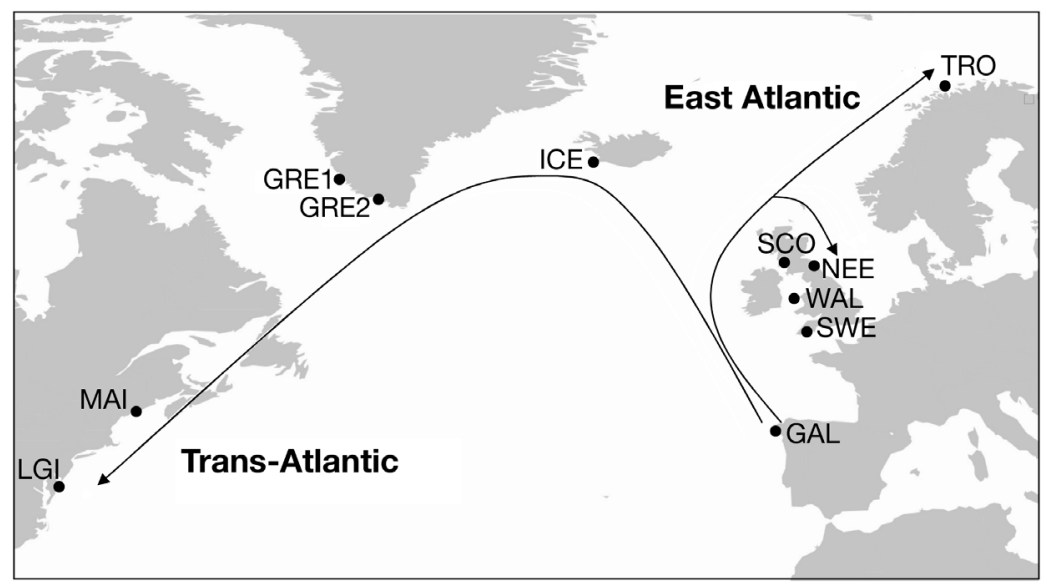

Fig. 1. Nucella lapillus. Putative post-glacial expansion routes. See Table 1 for population labels tests by computing a regression of $\mathrm{F}_{\mathrm{ST}} /\left(1-\mathrm{F}_{\mathrm{ST}}\right)$ on the natural logarithm of distance (Rousset 1996), using GENEPOP (Raymond \& Rousset 1995). Genetic affinities between populations were further assessed with Neighbour-Joining trees constructed from $F_{\mathrm{ST}}$ and from Nei et al.'s (1983) genetic distance. Genetic distance was computed with the MSA software and tree reconstruction carried out with PHYLIP 3.66 (Felsenstein 1993)

\section{RESULTS}

\section{Genetic diversity}

Amplification of one microsatellite locus (Nlw14) repeatedly failed in several individuals, in particular in west Atlantic populations, and was not examined further. Significant within-population departure from Hardy-Weinberg equilibrium was observed for loci Nlw11, Nlw17 and Nlw21. A Bonferroni-corrected significant deficit in heterozygotes existed at locus Nlw11 in one population (WAL1), at locus Nlw21 in one population (WAL2), and at locus Nlw17 in 5 populations (GAL1, DEV2, WAL2, SCO2, GRE2). Following these observations, we conducted all our analyses twice, including and excluding Nlw17, respectively but as both sets of analyses gave similar results, we present only the results based on 8 microsatellites (Nlw2, Nlw3, Nlw8, Nlw11, Nlw17, Nlw21, Nlw25 and Nlw27). The total number of alleles per locus varied from 7 to 23. East Atlantic populations were polymorphic (most frequent allele <0.95) at all loci, whereas the other populations were monomorphic as follows: Icelandic populations ICE1 and ICE2 at Nlw27, Maine MAI2 at Nlw25 and Nlw27, Greenlandic GRE1 at Nlw3, Nlw21, Nlw25 and Nlw27, Greenlandic GRE2 and Long Island LGI at Nlw2, Nlw3, Nlw21, Nlw25, Nlw27 (Table 1). Allele frequencies per locus and population are graphically shown in Fig. 2, and the raw data are available on request.

Three estimators of genetic diversity - A, expected number of alleles assuming SMM, averaged across loci, gene diversity or expected $\mathrm{He}$ and $\mathrm{V}_{\mathrm{R}}$, averaged across loci-were regressed on the distance from the Galician populations (representing the putative refugium populations), along the transAtlantic and the east Atlantic route. Differences in sample size between localities, in particular the smaller samples taken from the Galician and Maine populations, might cause underestima- 

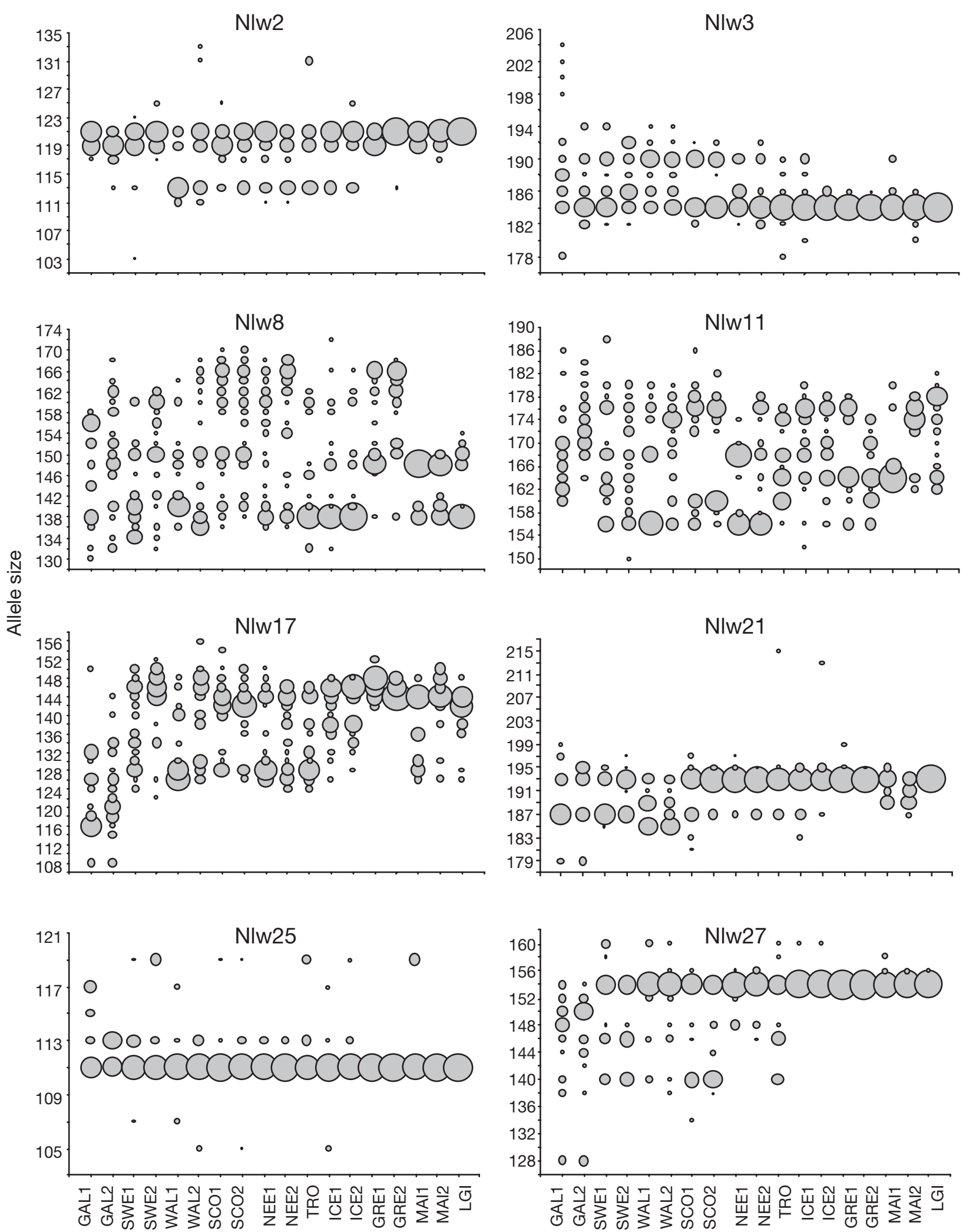

\section{Population}

Fig. 2. Nucella lapillus. Allele frequencies per locus and population. The area of each bubble is proportional to the frequency of a particular allele. See Table 1 for population labels 
tion of genetic diversity. Levels of genetic diversity in these 2 samples, however, were the highest observed in the east and west Atlantic respectively, indicating that small sample size did not significantly affect parameter estimation. Along the trans-Atlantic route, all 3 diversity parameters showed significant negative correlation with distance from the refugium, as would be expected under a model of unidirectional stepping stone expansion (Table 2). Along the east Atlantic route, both $\mathrm{He}$ and $\mathrm{A}$ showed a negative correlation with distance from the refugium, although the slope of the regression was not as steep as for the trans-Atlantic route (Fig. 3, Table 3). The value of $V_{R}$, however, did not decrease significantly with latitude along the European coast. The shallower cline of diversity parameters compared with the trans-Atlantic route (statistically significant in the case of $V_{R}$, with non-overlapping $95 \%$ confidence intervals), and the absence of a significant decrease in $V_{R}$ along the east-Atlantic route indicate that, despite long-distance migration across open seas, expansion along the European coast, in particular between the British Isles and Norway, either was not accompanied by bottlenecks as severe as those along the trans-Atlantic route, and/or involved relatively frequent long-distance dispersal events, in
Table 3. Nucella lapillus. Correlation coefficients R between diversity parameters and distance from Galicia. ${ }^{* * *} \mathrm{p} \leq 0.001$; ${ }^{*} \mathrm{p} \leq 0.05$; not significant at $\mathrm{p}>0.05 ; \mathrm{NS}$ : not significant

\begin{tabular}{|c|c|c|}
\hline \multirow{2}{*}{$\begin{array}{l}\text { Diversity } \\
\text { parameter }\end{array}$} & \multirow[b]{2}{*}{ East Atlantic } & \multirow[b]{2}{*}{ Transatlantic } \\
\hline & & \\
\hline $\mathrm{He}$ & $-0.693^{*}$ & $-0.834^{* * *}$ \\
\hline $\mathrm{A}$ & $-0.704^{*}$ & $-0.872^{* * *}$ \\
\hline $\mathrm{V}_{\mathrm{R}}$ & $-0.097^{\mathrm{NS}}$ & $-0.900^{* * *}$ \\
\hline
\end{tabular}

agreement with the expectation of a unidirectional multiple source dispersal (Table 2). In the west Atlantic, the populations from Maine showed higher values of gene and allele diversity than the other west Atlantic populations. Values from Maine were similar to those of the Icelandic populations. The variance in repeat number within populations from Maine, however, was much lower than within Icelandic populations, and similar to the Long Island and Greenlandic populations. This indicates that, in the West Atlantic, the populations from Maine seem either to have undergone more significant population growth, or were established earlier than populations from Long Island or Greenland.
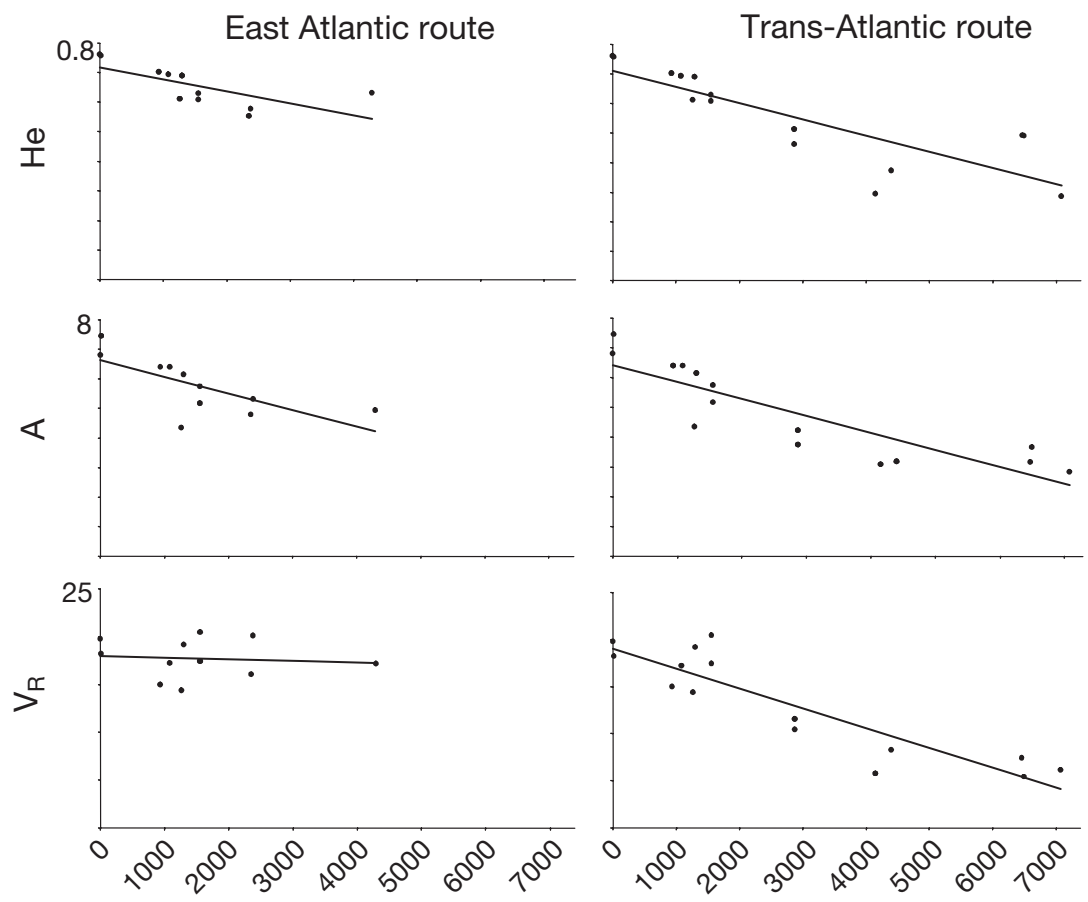

Distance $(\mathrm{km})$

Fig. 3. Nucella lapillus. Distribution of genetic diversity parameters along the putative east-Atlantic and trans-Atlantic expansion routes, expressed as distance from our furthest south-eastern sampling site (Galicia). He = gene diversity, averaged across loci; $A$ : allelic diversity, averaged across loci; $\mathrm{V}_{\mathrm{R}}$ : variance in repeat numbers, averaged across loci

\section{Isolation by distance}

Along the trans-Atlantic route, as expected from the unidirectional stepping stone model, we observed significant isolation by distance $(\mathrm{r}=0.60$, $\mathrm{p}=0.006)$. On the east Atlantic route, however, no significant correlations were found (isolation by distance: $\mathrm{r}=$ $0.33, \mathrm{p}=0.20$ ), as expected from the unidirectional multiple source model of expansion (Fig. 4).

\section{Genetic structure}

$\mathrm{F}_{\mathrm{ST}}$ values between sites within localities varied from less than 0.001 in Iceland to 0.068 in Galicia. The genetic distance between the 2 Greenlandic populations, however, was much higher $\left(\mathrm{F}_{\mathrm{ST}}=0.17\right)$. Regional values of 2 different estimators of $F_{S T}$ and $R_{S T}$ are shown in Table 4. Estimated values of $\mathrm{F}_{\mathrm{ST}}$ are usually lower than the estimators of $R_{S T}$, as expected when gene flow is low and/or mutation rate high (Bal- 

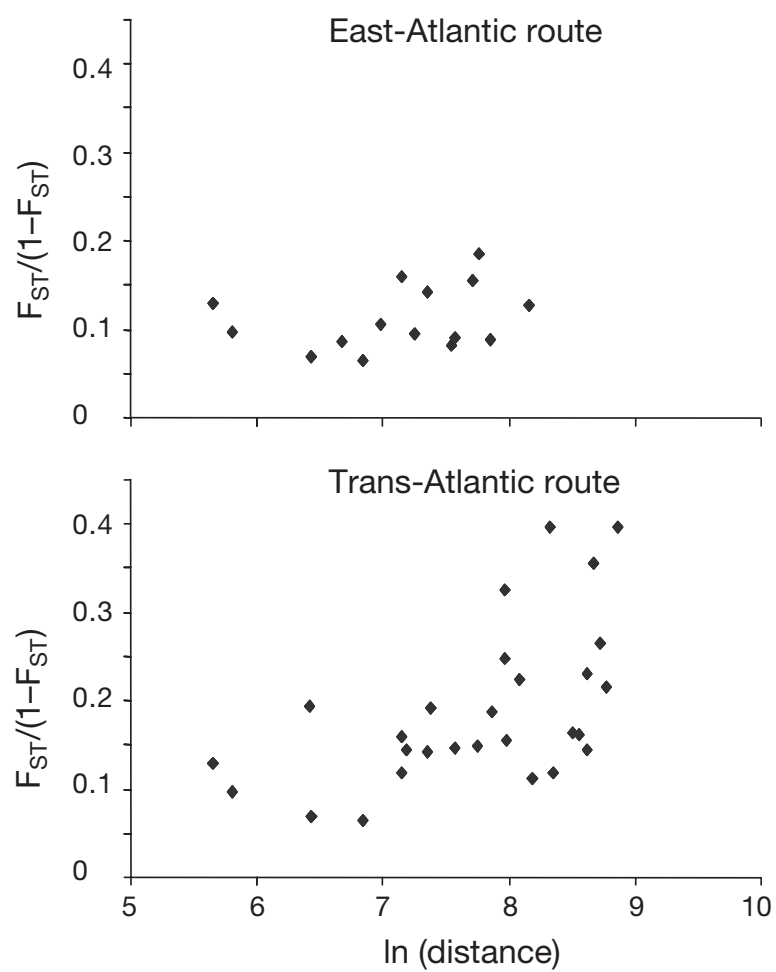

Fig. 4. Nucella lapillus. Isolation by distance along the putative east-Atlantic and trans-Atlantic expansion routes

loux \& Lugon-Moulin 2002). Estimators of $\mathrm{R}_{\mathrm{ST}}$ derived from 2 different methods were much more variable than corresponding estimators of $\mathrm{F}_{\mathrm{ST}}$. Of the 2 estimators of $\mathrm{R}_{\mathrm{ST}}$, UR $\mathrm{UR}_{\mathrm{ST}}$ (Goodman 1997) might be the more appropriate here, since it takes into account differences in variability among loci. The discrepancy between $\mathrm{F}_{\mathrm{ST}}$ and $\mathrm{UR}_{\mathrm{ST}}$ is higher for the global measure of genetic distance than for the East Atlantic and West Atlantic regions. Values of $\mathrm{F}_{\mathrm{ST}}$ and $\mathrm{R}_{\mathrm{ST}}$ were not significantly different in the Greenlandic populations. For the global population and the east Atlantic region, the

Table 4. Nucella lapillus. Regional values of 2 estimators of $F_{\mathrm{ST}}\left(\mathrm{G}_{\mathrm{ST}}\right.$ ': Nei 1973; $\theta$ : Weir \& Cockerham 1983) and 2 estimators of $\mathrm{R}_{\mathrm{ST}}\left(\mathrm{R}_{\mathrm{ST}}\right.$ : Rousset 1996; UR $\mathrm{UT}_{\mathrm{ST}}$ : Goodman 1997), and values of the same estimators between east and west Atlantic pooled populations

\begin{tabular}{|c|c|c|c|c|}
\hline \multirow[t]{2}{*}{ Region } & \multicolumn{2}{|c|}{ Estimators of $\mathrm{F}_{\mathrm{ST}}$} & \multicolumn{2}{|c|}{ Estimators of $\mathrm{R}_{\mathrm{ST}}$} \\
\hline & $\mathrm{G}_{\mathrm{ST}}{ }^{\prime}$ & $\theta$ & $\mathrm{R}_{\mathrm{ST}}$ & $\mathrm{UR}_{\mathrm{ST}}$ \\
\hline Global & 0.16 & 0.15 & 0.29 & 0.25 \\
\hline East Atlantic & 0.12 & 0.11 & 0.23 & 0.18 \\
\hline West Atlantic $^{a}$ & 0.13 & 0.14 & 0.37 & 0.18 \\
\hline Greenland & 0.17 & 0.17 & 0.12 & 0.16 \\
\hline East vs West & 0.095 & 0.09 & 0.11 & 0.14 \\
\hline
\end{tabular}

estimated value of $\mathrm{R}_{\mathrm{ST}}$ lies outside the $95 \%$ confidence interval of $\theta$. The 2 Neighbour-Joining trees of the populations sampled (Fig. 5) both identify 3 principal clusters: one 'south European' cluster comprising Galician and southwest English populations, and 2 clusters with northeast and west Atlantic populations, respectively. Only the position of the Tromsø population is ambiguous, as Nei's distance places it closer to the South European cluster, while using $\mathrm{F}_{\mathrm{ST}}$ distance we would infer a closer relationship with other northeastern populations.

\section{DISCUSSION}

Our results confirm the conclusion from mt-DNA studies that North American populations of Nucella lapillus are the result of post-glacial recolonization from Europe (Wares \& Cunningham 2001). The relatively low levels of genetic structure (for a direct developer) recorded here seem to indicate a higher rate of dispersal in $N$. lapillus than might be expected from the lack of a planktonic larval stage, as we also concluded from studies at a more regional scale (Colson \& Hughes 2004). A spurious underestimation of genetic structure, however, can result if $\mathrm{F}_{\mathrm{ST}}$ is used in a system with low migration and/or high mutation rate (Balloux \& Lugon-Moulin 2002). Values of $\mathrm{R}_{\mathrm{ST}}$ suggest that $\mathrm{F}_{\mathrm{ST}}$ might indeed have been somewhat underestimated. The discrepancy, however, is not great and is most noticeable when considering regions straddling long open-sea distances potentially acting as barriers to gene flow. A model of higher rates of dispersal, at least along some expansion routes, is further supported by the results of our genetic diversity analysis. Along the European coast, patterns of genetic variation indicate that long-distance dispersal is likely to have been relatively frequent and greater than expected for a direct developer. Moreover, no pattern of isolation by distance is discernible. This supports a model whereby northern European populations were established by a relatively high number of migrants during one or several long-distance dispersal events, probably from multiple sources. The uncertainty about the genetic affinities of the Troms $ø$ population supports a hypothesis of repeated, independent, long-distance migration events to the Norwegian coast. In contrast, expansion across the Atlantic involved several intense bottlenecks, resulting in a steep decline of all 3 parameters of genetic diversity with distance from source populations (England et al. 2003), as well as a total loss of polymorphism at several loci. One such bottleneck occurred between Europe and Iceland, another between Iceland and the eastern North American coast. The higher genetic diversity, at least in terms of 


\section{A}

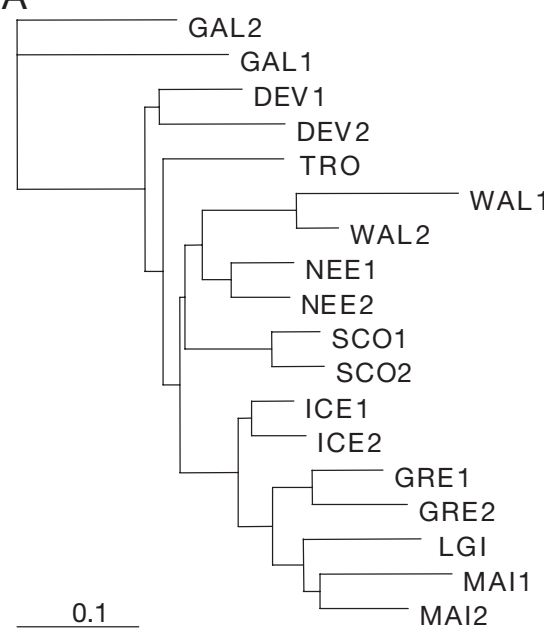

$B$

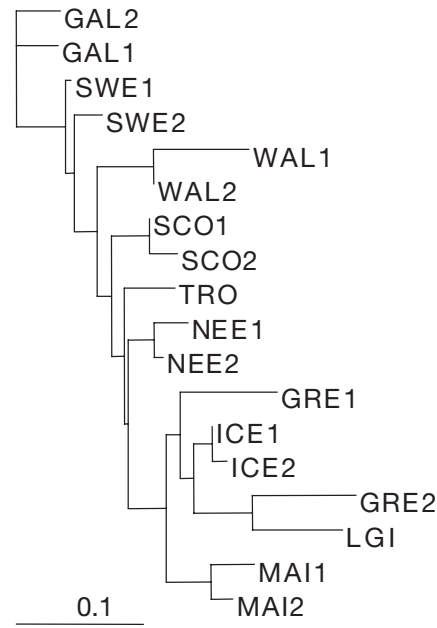

Fig. 5. Nucella lapillus. Unrooted Neighbour-Joining tree of the sampled populations based on (A) Nei et al. (1983) genetic distance and (B) pairwise $\mathrm{F}_{\mathrm{ST}}$ values. See Table 1 for population labels

Although it is widely accepted that oceanic currents play a major role in the distribution of planktonic larvae, their role in the dispersal of direct developers might have been underestimated. There is increasing evidence that currents do indeed significantly affect the distribution and dispersal, and therefore the genetic structure of non-planktonic species (Hoskin 2000). The apparent paradox that many isolated oceanic islands are inhabited by more species of direct developers or brooders than species with planktonic larvae can be explained in terms of the differential effect of surface currents on these groups of species: small pioneer populations of direct developers will be maintained within a restricted area, facilitating mating, while planktonic larvae might not be retained (Johannesson 1988). But how likely is the occurrence of dispersal by rafting in Nucella lapillus? Ingolfs-

allelic diversity and gene diversity, of populations in Maine is likely to be the result of a rapid post-colonization expansion, as $V_{R}$ fails to show the same relative increase. Populations along the trans-Atlantic route also show isolation by distance. These genetic patterns are compatible with a model of stepwise migration involving long-distance dispersal of a few individuals across open seas.

The east-Atlantic route, too, contains open-water barriers, in particular the North Sea between the British Isles and the Norwegian coast, which judging from ice cover during the LGM, the disappearance of the English Channel, and the lack of suitable habitat along the southern North Sea coast, was the most likely pathway for northerly expanding populations. The apparent greater frequency of colonization events along the east Atlantic route compared with the transAtlantic route can be explained tentatively by the effect of oceanic currents on the dispersal of Nucella lapillus. The North Atlantic and Norwegian currents flow northward around the tip of Scotland and along the Norwegian coast (Fig. 14.2 in Tomczak \& Godfrey 2003). Migrants rafting from northern Britain therefore would be more likely to be transported towards Norway than Iceland. This would explain the occurrence of stronger bottlenecks between Britain and Iceland than to Norway. Likewise, the second barrier from Iceland to North America would result from the fact that, although rafting could potentially occur along the Irminger, West Greenland and Labrador currents (Tomczak \& Godfrey 2003), these cold arctic currents are not favourable to the survival of temperate/boreal species such as $N$. lapillus. son (1995) observed 39 taxa of intertidal organisms rafting on clumps of seaweed more than $100 \mathrm{~km}$ from the coast of Iceland, among them 2 species of Littorina. Juvenile $N$. emarginata can drift with water currents using mucous threads (Martel \& Chia 1991), a feature common to several molluscan taxa. It seems reasonable therefore to suggest that rafting might also be an important factor of dispersal in N. lapillus.

The present study provides a detailed phylogeographic analysis of the post-glacial expansion of an intertidal organism lacking pelagic larvae, and has allowed us to formulate working hypotheses on factors influencing Nucella lapillus dispersal. It is hoped that the addition of other taxa will help shed light on the dynamics of the recovery of intertidal rocky shore ecological assemblages linked to global climatic oscillations.

Acknowledgements. We are grateful to E. Rolan-Alvarez and J. Rock for providing specimens from Galicia and Maine, respectively. G. H. Petersen provided invaluable information on the location of Greenlandic populations, and W. Fernandes provided technical support with DNA extractions. This work was funded by the European Union (EUMAR project, grant number EVK3-CT-2001-00048 to R.N.H.). Conceptual input and logistic support were gained from CORONA (Coordinating Research on the North Atlantic, funded by the National Science Foundation, USA).

\section{LITERATURE CITED}

Balloux F, Lugon-Moulin N (2002) The estimation of population differentiation with microsatellite markers. Mol Ecol 11:155-165 
Bohonak AJ (1999) Dispersal, gene flow, and population structure. Q Rev Biol 74:21-45

Clark JS (1998) Why trees migrate so fast: confronting theory with dispersal biology and the paleorecord. Am Nat 152: 204-224

Colson I, Goldstein DB (1999) Evidence for complex mutations at microsatellite loci in Drosophila. Genetics 152: $617-627$

Colson I, Hughes RN (2004) Rapid recovery of genetic diversity of dogwhelk (Nucella lapillus) populations after local extinction and recolonisation contradicts predictions from life-history characteristics. Mol Ecol 13:2223-2233

Dieringer D, Schlötterer C (2003) MICROSATELLITE ANALYSER (MSA): a platform independent analysis tool for large microsatellite data sets. Mol Ecol Notes 3: 167-169

England PR, Osler GHR, Woodworth LM, Montgomery ME, Briscoe DA, Frankham R (2003) Effects of intense versus diffuse population bottlenecks on microsatellite genetic diversity and evolutionary potential. Conserv Genet 4: 595-604

Felsenstein J (1993) PHYLIP (Phylogeny Inference Package). University of Washington, Seattle

Goodman SJ (1997) $\mathrm{R}_{\mathrm{ST}}$ Calc: a collection of computer programs for calculating estimates of genetic differentiation from microsatellite data and determining their significance. Mol Ecol 6:881-885

Goudet J (1995) FSTAT (vers. 1.2): a computer program to calculate $F$ statistics. J Hered 86:485-486

Govindarajan AF, Halanych KM, Cunningham CW (2005) Mitochondrial evolution and phylogeography in the hydrozoan Obelia geniculata (Cnidaria). Mar Biol 146: 213-222

Hewitt G (2000) The genetic legacy of the Quaternary ice ages. Nature 405:907-913

Hoskin MG (2000) Effects of the East Australian current on the genetic structure of a direct developing muricid snail (Bedeva hanleyi, Angas): variability within and among local populations. Biol J Linn Soc 69:245-262

Ingolfsson A (1992) The origin of the rocky shore fauna of Iceland and the Canadian Maritimes. J Biogeogr 19: 705-712

Ingolfsson A (1995) Floating clumps of seaweed around Ice-

Editorial responsibility: Howard Browman (Associate Editorin-Chief), Storebø, Norway land: natural microcosms and a means of dispersal for shore fauna. Mar Biol 122:13-21

Johannesson K (1988) The paradox of Rockall: why is a brooding gastropod (Littorina saxatilis) more widespread than one having a planktonic larval dispersal stage (L. littorea)? Mar Biol 99:507-513

Kawai K, Hughes RN, Takenaka O (2001) Isolation and characterization of microsatellite loci in the marine gastropod Nucella lapillus. Mol Ecol Notes 1:270-272

Kristensen K, Petersen GH (1977) The Narssaq Report. In: Marine Biology. Institute of Petrology, University of Copenhagen, Copenhagen, p 62-63

Kushta SR , Tan AM (2004) Isolation by distance and postglacial range expansion in the rough-skinned newt, Taricha granulosa. Mol Ecol 14:225-244

Martel A, Chia FS (1991) Drifting and dispersal of small bivalves and gastropods with direct development. J Exp Mar Biol Ecol 150:131-147

Mörch OAL (1857). Fortegnelse over Grønlands Bløddyr. Louis Kleins Bogtrykkeri, Copenhagen

Nei M (1973) Analyses of gene diversity in subdivided populations. Proc Natl Acad Sci USA 70:3321-3323

Nei M, Maruyama T, Chakraborthy R (1975) The bottleneck effect and genetic variability in populations. Evolution 29: $1-10$

Nei M, Tajima F, Tateno Y (1983) Accuracy of estimated phylogenetic trees from molecular data. J Mol Evol 19: 153-170

Raymond M, Rousset F (1995) GENEPOP (version 1.2): population genetics software for exact test and ecumenism. J Hered 86:248-249

Rousset F (1996) Equilibrium values of measures of population subdivision for stepwise mutation processes. Genetics 142:1357-1362

Slatkin M (1995) A measure of population subdivision based on microsatellite allele frequency. Genetics 139:457-462

Tomczak M, Godfrey JS (2003) Regional oceanography: an introduction, 2nd edn. Daya Publishing House, Delhi

Wares JP, Cunningham CW (2001) Phylogeography and historical ecology of the North Atlantic intertidal. Evolution 55:2455-2469

Weir BS, Cockerham CC (1984) Estimating F-statistics for the analysis of population structure. Evolution 38:1358-1370

Submitted: September 25, 2006; Accepted: January 5, 2007

Proofs received from author(s): July 23, 2007 